\title{
Design of rain shelters for studying water relations of range- land shrubs
}

\author{
P.W. JACOBY, R.J. ANSLEY, AND B.K. LA WRENCE
}

\section{Abatract}

A low-cost, fixed-place, subcanopy rain shelter was constructed to facilitate studying water relations of honey mesquite (Prosopis glandulosa) growing in north Texas rangeland. This shelter, combined with a supplemental irrigation system and a barrier to contain Iateral roots, permitted the study of molsture influences on transpiration, xylem pressure potential, and leaf temperature on large woody plants in the field.

Key Words: honey mesquite (Prosopis glandulosa), physlology, soil moisture, water use

Information regarding water use by woody range plants is needed to aid in selection of water-efficient varieties for certain reclamation and improvement programs and to quantify relative water use of noxious shrubs. Water use studies with shrubs have been complicated by size and longevity of woody plants and the difficulty in transplanting adequate numbers of large plants to areas of controlled environment. Water relations studies conducted in greenhouse environments may not relate accurately to natural conditions where leaves develop thicker cuticles and are exposed to the abiotic environment. Moreover, seasonal variation in climatic conditions has demanded long-term field studies to encompass the range of moisture conditions encountered in natural environments.

Use of rain shelters has facilitated studies to evaluate drought resistance of crop species (Arkin et al. 1976, Clawson et al. 1986).

Authors are professor, post-doctoral research associate, and technician, respectively, Texas Agricultural Expperiment Station, P.O. Box 1658, Vernon 76384.

Research was funded in part by University Lands-Surface Interests, Univ. Texas System, Midland; E. Paul and Helen Buck Waggoner Foundation, Vernon, Texas, and was conducted on the W.T. Wageoner Estate, Vernon, Texas.

This article is being published as technical article TA-22540 from the Texas Agricultural Experiment Station.

Manuscript accepted 3 September 1987.
Such shelters must be functional only during periods of precipitation and require complicated mechanisms to move the shelter into place in order to shield the crop from the rain (Upchurch et al. 1983). With large woody plants, the design of the structure can be modified to shield the availability of moisture without covering the canopy of the plant.

A fixed-place shelter installed subcanopy was the proposed design to meet requirements of a study to place designated degrees of moisture stress on the woody shrub, honey mesquite (Prosopis glandulosa). The study was facilitated by lack of subsurface water on the study site which placed plant dependence on moisture in the upper soil profile. The shelter described in this paper, when used in conjunction with root containment techniques and irrigation, incorporated aspects of controlled and natural environments for studying shrub physiology.

\section{Materials and Methods}

Following installation of a vertical metal barrier to a depth of $250 \mathrm{~cm}$, which effectively containerized a multistemmed honey mesquite tree ( $3.5 \mathrm{~m}$ tall) within a $106-\mathrm{m}^{3}$ soil column (Ansley et al. 1988, a subcanopy rain shelter comprised of a wood frame and plastic covering was constructed. Six $1-\mathrm{cm}$ diameter posts were used to support the hexagonal-shaped frame which was constructed from 5 by $10-\mathrm{cm}$ framing lumber as shown in Figure 1.

Wooden footings were placed at critical points near midpoints of the parallel boards to provide additional strength. Braces of 2.5 by $10-\mathrm{cm}$ boards were nailed across the bottoms of the $5 \times 10$ 's and fastened parallel to the midrib to prevent the parallel boards from warping.

After framing was completed, a trickle irrigation system made of $1.25-\mathrm{cm}$ black plastic pipe was suspended along the bottom side (Fig. 2). The irrigation system may be optional, depending on 


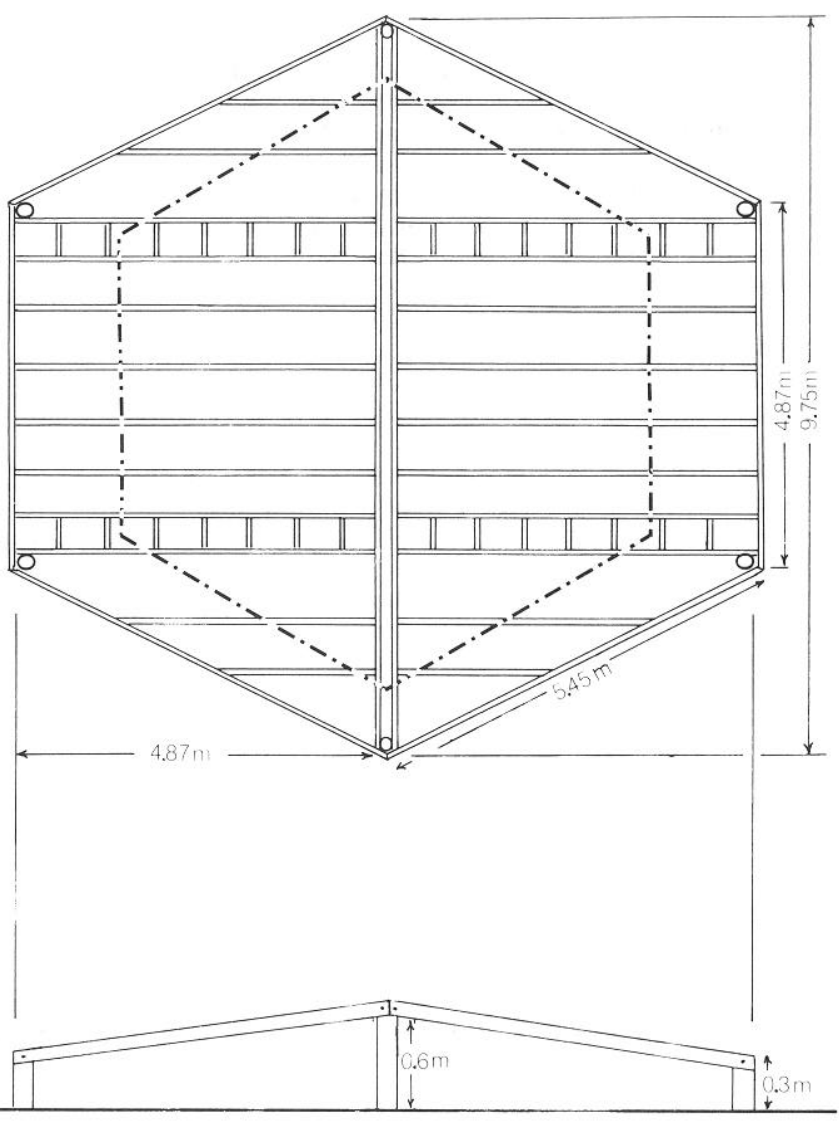

Fig. 1. Overhead and side views of the structural framework for a subcanopy rainout shelter. Broken line indicates the region of a barrier against lateral plant roots. Cross-braced areas are for walkways. Structural footings are described in the text.

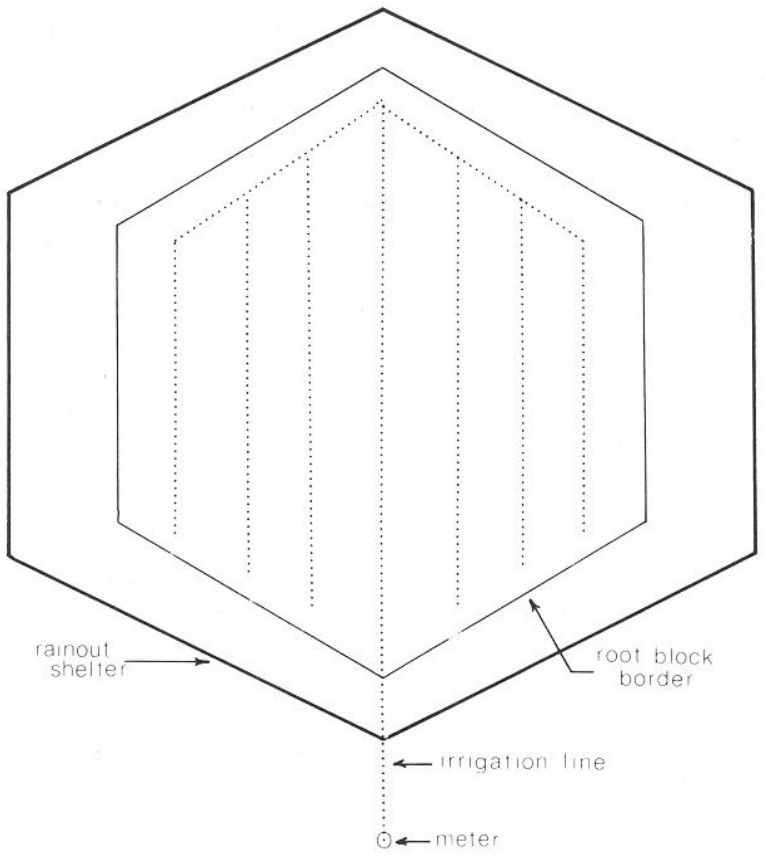

Fig. 2. Schematic diagram illustrating the arrangement of the trickle irrigation system (dotted lines) which was at tached to the structural framework of the rain shelter (outer border) to provide measured amounts of water to the containerized tree (inner border). Lines are $1 \mathrm{~m}$ apart and emitters are $30 \mathrm{~cm}$ apart to distribute systematically over the containerized area.

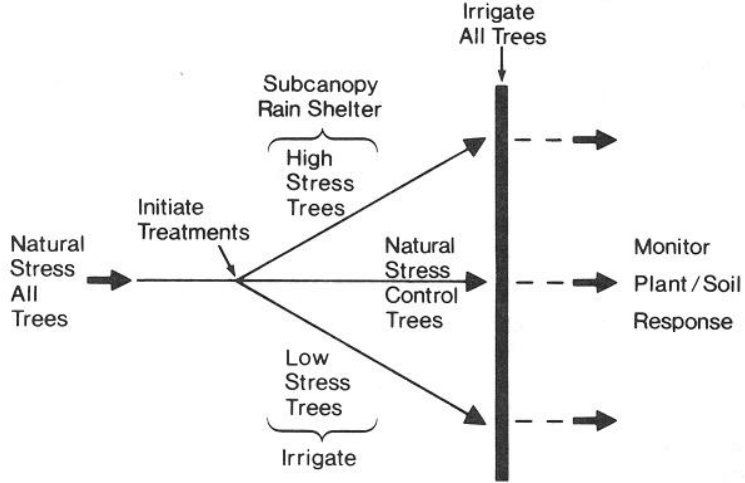

Fig. 3. Flow diagram illustrating how subcanopy rain shelter and trickle irrigation were used to impose 3 levels of stress in honey mesquite prior to treatment of all trees with a similar pulse of moisture.

objectives of the study. Our design provided for periodic irrigations to trigger specific physiological events (Fig. 3). Water was stored in a 20,000-liter tank trailer and was delivered through an underground PVC line (2.5-cm diam.) via an electric pump and pressure tank. Power was provided by a $4.5-\mathrm{kw}$ portable generator. A control valve and water meter were installed at each tree to regulate and measure the amount of water delivered.

A layer of $2.5-\mathrm{cm}$ mesh poultry netting was stretched across the top of the frame and secured with a pneumatic staple gun. The portion around the stems was cut and rewired to provide support around the central portion of the tree.

A layer of 6-mil thick clear plastic was placed over the poultry netting and frame to provide the protective cover for the shelter (Fig. 4). The plastic was cut and resealed with mending tape around

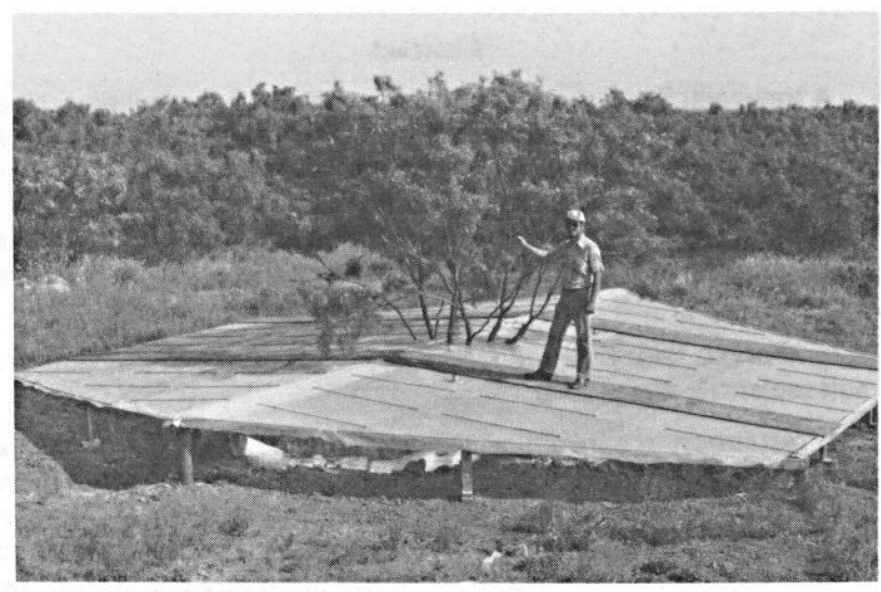

Fig. 4. A completed shelter in place beneath the canopy of a honey mesquite tree on the W.T. Waggoner Estate near Vernon, Texas.

the tree stems to provide a water-tight fit. A layer of 5-cm mesh poultry netting was placed over the lower two-thirds of the shelter and stapled to the frame. Slats of wooden lath were stapled to the frame to secure the plastic and provide additional protection against wind damage.

To allow access to the tree canopy for physiological measurements, wooden walkways were incorporated into the shelter design by nailing $1.8-\mathrm{cm}(.75 \mathrm{inch})$ thick plyboard to the frame. These walkways, located on each side of the tree, also provided access to $5-\mathrm{cm}$ aluminum access tubes which extended through the surface of the shelter for measurement of soil moisture using the neutron attenuation method. Molded plastic collars were fitted around the access tubes to prevent moisture flow down the outside of the tube. 
The tubes were sealed with neoprene stoppers on top and permanently on the bottom. A hygrothermograph was placed beneath one shelter and records were compared with those taken from a nearby nonsheltered tree.

\section{Discussion}

Total cost of materials used in the construction of a single rain shelter was about $\$ 625$, which included that portion or the irrigation system situated at the tree. Labor to construct each shelter was estimated at 100 man-hours. Labor per shelter decreased during construction of several shelters owing to the experience factor. Costs of materials are shown in Table 1 and are based on actual prices FOB Vernon, Texas, in 1986. Comparable costs for motorized, metal shelters used in crop studies are considerably more expensive than the model used in our study, costing more than $\$ 20,000$ for a single rain shelter (Upchurch et al. 1983).

Table 1. Coats of items required to construct a sub-canopy rain thelter in 1996. Measurements are expreased in English in accordance with common uange by the construction induatry.

\begin{tabular}{|c|c|c|c|}
\hline Description of Items & $\begin{array}{l}\text { Item } \\
\text { cost }\end{array}$ & $\begin{array}{l}\text { No. } \\
\text { No. }\end{array}$ & $\begin{array}{r}\text { Group } \\
\text { cost }\end{array}$ \\
\hline 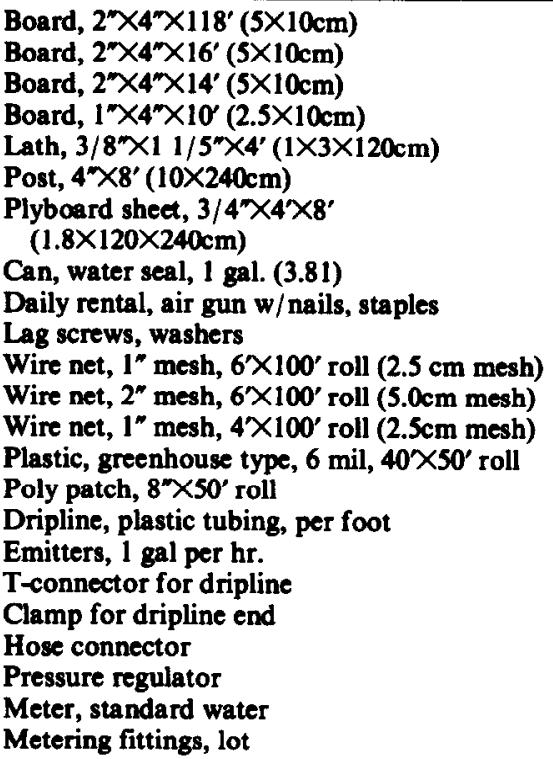 & $\begin{array}{r}11.49 \\
10.75 \\
17.50 \\
.29 \\
53.30 \\
27.24 \\
41.25 \\
124.83 \\
7.87 \\
.05 \\
.11 \\
.80 \\
.20 \\
.68 \\
5.00 \\
46.00 \\
6.56\end{array}$ & $\begin{array}{r}4 \\
1 \\
3 \\
16 \\
1 \\
1 \\
2 / 3 \\
1 \\
1 \\
170 \\
50 \\
5 \\
6 \\
1 \\
1 \\
1 \\
1\end{array}$ & $\begin{array}{r}45.96 \\
10.75 \\
52.50 \\
4.64 \\
53.30 \\
27.24 \\
27.48 \\
124.83 \\
7.87 \\
9.18 \\
5.50 \\
4.00 \\
1.20 \\
.68 \\
5.00 \\
46.00 \\
6.56\end{array}$ \\
\hline TOTAL & & & $\$ 625.12$ \\
\hline
\end{tabular}

The original plastic covering photodegraded and became torn during the first 6 weeks of use. Replacement with a greenhousequality plastic solved this problem, but increased initial cost of the shelter. Use of poultry netting to suspend and secure the plastic lining worked well, and along with wood lath, prevented wind damage during several summer storms. The plastic was removed following summer use, and shelters were nonfunctional during winter. Removal of the plastic enabled the soil within the root container and below the rain shelter to recharge during winter dormancy.

Previous work has indicated shelters reduce wind movement and solar radiation, depending on the design (Dugas and Upchurch 1984). However, air movement beneath our shelter was sufficient

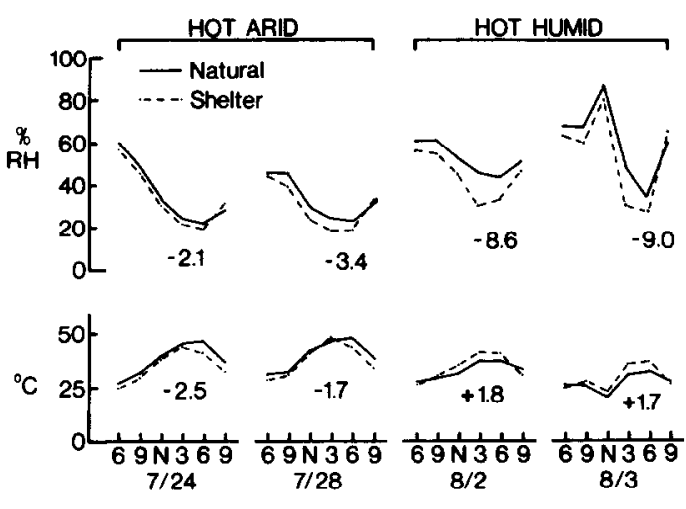

Fis.5. Daily relative humidities and air temperature under ambient conditions and beneath the rain shelter on typical-hot arid and hot-humid days during mid summer 1986. Values indicate maximum difference (shelternatural) occurring on each day.

to reduce che differences in air temperatures between the subshelter and nonsheltered stations to a minimum. On a typical hot, arid day in midsummer relative humidities averaged 2 to $3 \%$ lower, and air temperatures 1.5 to $2.5^{\circ} \mathrm{C}$ lower beneath the shelter than ambient conditions (Fig. 5). On hot, humid days humidities averaged 8 to 9\% lower and temperatures 1 to $2^{\circ} \mathrm{C}$ higher beneath the shelters than under ambient conditions.

Slightly raised earth berms around the root container prevented overland flow of water from reaching the interior portion of the tree under the rain shelter during high intensity storms. A slight amount of wind-driven moisture reached a small portion of the area beneath the shelter, but was unsufficient to alter any measured effects on the trees.

The grass community beneath the shelter survived, albeit in a somewhat dormant state. Two periods of irrigation via the trickle system appeared to rejuvenate the grass community enough to maintain life.

Overall, the shelter performed to our expectations and accomplished our goals at a fraction of the cost of more complicated shelters currently in use. The primary disadvantage of the shelter was the relatively poor access to the subshelter area after the wire mesh was installed and the slight changes which occurred in temperature and RH. Variations of our design could provide access ports in the frame to allow subshelter access by removal of panels or flaps in the plastic cover and increase ventilation. However, any openings in the plastic cover offer an opportunity for improper seal during rain events, which could alter or interrupt a study. Moreover, integrity of the plastic sheets was better maintained during high winds when uncut.

\section{Literature Cited}

Andey, R.J., P.W. Jacoby, and B.K. Lawrence. 19a8. Root containerization for physiological studies of shrubs and trees on rangeland. J. Range Manage. 41:90-91.

Arkin, G.F., J.T. Ritchie, M. Thompeon, and R. Chaison. 1976. A rainout shelter installation for studying drought stress. Agron. J. 68:429-431.

Clawson, K.L., B.L. Blad, and J.E. Specht. 1986. Use of portable rainout shelters to induce water stress. Agron. J. 78:120-123.

Dugas, W.A., and D.R. Upchureh. 1984. Microclimate of a rainfall shelter. Agron. J. 76:867-871.

Upehurch, D.R., J.T. Ritehie, and M.A. Foale. 1983. Design of a large dual-structure rainout shelter. Agron. J. 75:845-848. 